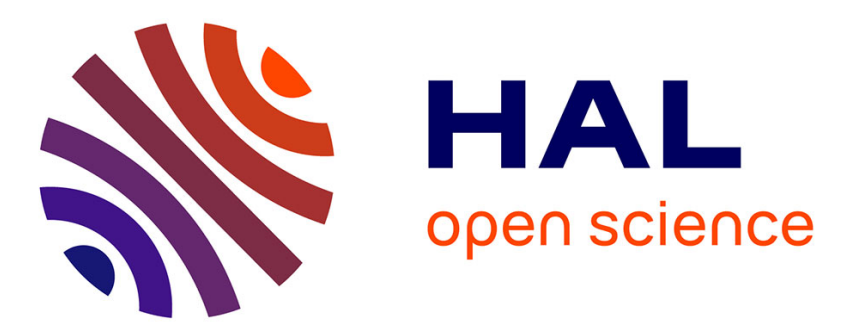

\title{
Copper complexing properties of dissolved organic matter: PARAFAC treatment of fluorescence quenching
}

Stéphane Mounier, Huiyu Zhao, Cédric Garnier, Roland Redon

\section{To cite this version:}

Stéphane Mounier, Huiyu Zhao, Cédric Garnier, Roland Redon. Copper complexing properties of dissolved organic matter: PARAFAC treatment of fluorescence quenching. Biogeochemistry, 2011, 106, pp.107-116. 10.1007/s10533-010-9486-6 . hal-01096841

\section{HAL Id: hal-01096841 \\ https://hal-univ-tln.archives-ouvertes.fr/hal-01096841}

Submitted on 5 Jan 2015

HAL is a multi-disciplinary open access archive for the deposit and dissemination of scientific research documents, whether they are published or not. The documents may come from teaching and research institutions in France or abroad, or from public or private research centers.
L'archive ouverte pluridisciplinaire HAL, est destinée au dépôt et à la diffusion de documents scientifiques de niveau recherche, publiés ou non, émanant des établissements d'enseignement et de recherche français ou étrangers, des laboratoires publics ou privés. 


\title{
Copper complexing properties of dissolved organic matter: PARAFAC treatment of fluorescence quenching
}

\author{
Stéphane Mounier $\cdot$ Huiyu Zhao \\ Cédric Garnier $\cdot$ Roland Redon
}

Received: 31 August 2009/Accepted: 2 June 2010/Published online: 9 August 2010

(C) Springer Science+Business Media B.V. 2010

\begin{abstract}
Fluorescence quenching of the fluorescence is a useful method to determine copper complexing properties of the dissolved organic matter. This technique provides express results often by choosing one or two excitation-emission fluorescence measurement for a straight range of concentration. That why it is not representative of the whole sample. On another hand, using total luminescence spectra gives lots of information that is difficult to manipulate in term of complexing properties. This work focus on a fluorescence quenching experiment carried out on a filtered black water from Rio Negro from north Brazil (Sao Gabriel da Cachoeira) using excitation emission matrix of fluorescence (EEMF) with a large range of copper concentration. Indeed, metal additions were performed using logarithmic increments of the total copper concentration to cover a wide range of concentration from $1.7 \times 10^{-9}$ to $10^{-3} \mathrm{~mol} \mathrm{l}^{-1}$. These data were treated by two different ways for comparison: on the one hand, data treatment were
\end{abstract}

S. Mounier · H. Zhao $(\bowtie) \cdot$ C. Garnier

Laboratoire d'étude de PROcessus de Transferts et d'Échanges dans l'environnement (PROTEE-EA 3819) CAPTE, Université du Sud Toulon Var, BP 20132, 83957 La Garde Cedex, France e-mail: huiyu_zhao@hotmail.fr

\section{R. Redon}

Laboratoire d'étude de PROcessus de Transferts et d'Échanges dans l'environnement (PROTEE-EA 3819)_ ISO, Université du Sud Toulon Var, BP 20132, 83957 La Garde Cedex, France computed, as usually, at different fluorescence intensity positions using multi-response wavelength method with two ligand, and, on the another hand, a statistical method, parallel factor analysis (PARAFAC), was applied to extract fluorescent component. Then a fitting was done on these PARAFAC components with one or two complexing sites each one. Results show that PARAFAC enables quantitative evaluation of complexing parameters for copper as good as certain multi-response methods: $\mathrm{L}_{1 \mathrm{~T}} 16.2 \times 10^{-6} \mathrm{~mol} \mathrm{l}^{-1}$ $\left(5.0<\log \left(\mathrm{K}_{1}\right)<5.8\right)$ and $\mathrm{L}_{2 \mathrm{~T}} 3.0 \times 10^{-4} \mathrm{~mol} \mathrm{l}^{-1}$ $\left(2.8<\log \left(\mathrm{K}_{2}\right)<3.9\right)$. PARAFAC confirms that for this natural sample only two fluorescent ligands are present with two types of site for each component. No residual fluorescence was detected by the statistical treatment. Wall surface interferences were pointed-out as phenomenon to be solve to overcome the limiting efficiency of the total copper concentration range.

Keywords Natural organic matter - Fluorescence quenching . Excitation emission matrix of fluorescence · PARAFAC - Copper complex

\section{Introduction}

Natural organic matter (NOM) is a complex mixture of naturally occurring organic material resulting from the decay of plant and animal residues. The widespread occurrence of NOM, particularly its most 
soluble fractions, fulvic acids and humic acids, in soils, sediments and waters, and the existence in their molecules of chemical reactive groups, such as carboxylic and hydroxylic structures, are responsible for their important environmental role. For example, they function as acid-base buffers and bind to metal ions (Esteves da Silva and Machado 1995; Smith and Kramer 1999). Their complexing properties versus cations were studied a lot due to importance in trace metal cycle and pH-buffer properties (Cabaniss 1992; Esteves da Silva and Machado 1995; Esteves da Silva et al. 1996). A famous way to measure complexing properties of the NOM is using its fluorescence properties (Cabaniss 1992). Since Ryan and Weber (1982) fluorescent dissolved organic matter (FDOM) was studied by using fluorescence quenching. As this method is easy to use, lots of measurements were done on FDOM from several types of samples: seawater (Esteves da Silva and Machado 1996), river (Mounier et al. 1999), complex mixture (Smith and Kramer 1998) or extracted organic matter (Cabaniss 1992; Esteves da Silva et al. 1998; Smith and Kramer 1999; Dudal et al. 2006; Manciulea et al. 2009). Even if it is common in use, the fluorescence quenching suffers serious drawbacks: (1) It exclusively concerns the fluorescent functions, and the result of a quenching experiment is only a part of the DOM response (Smith and Kramer 2000), (2) The choice of the observation wavelength is determinant. If the emission wavelength around $450 \mathrm{~nm}$ has generally been used at the beginning of fluorescence quenching history, many authors preferred using either single peak intensity (Esteves da Silva et al. 1998), or either a multi-peak treatment on a fluorescence matrix (Luster et al. 1996) or a synchronous spectra (Cabaniss 1992; Esteves da Silva and Machado 1995), (3) The covered range of metal concentration is generally distributing among $10^{-6}$ and $10^{-3}$ mol $1^{-1}$ which is higher than the natural concentration of trace metals, (4) Fluorescence is pH dependent (Esteves da Silva et al. 1996).

Since Coble (1996), FDOM is observed by measuring excitation and emission matrix of fluorescence (EEMF) and by locating peaks of fluorescence on the map to detect fluorescent compounds in the sample. Hence, EEMF could be used during fluorescence quenching experiment to detect FDOM behaviour in presence of metal. As the whole fluorescence of the sample is observed, several methods were developed to calculated complexing parameters. Multi-response treatments of EEMF have been done using multi-peak intensities independently (Luster et al. 1996) or coupled (Smith and Kramer 1998, 2000). Moreover, during fluorescence quenching experiments several problems occur: maximum peak position could move due to inner filter effect, residual fluorescence from unquenched fluorescent species could be present, etc.. Hence, the choice of a fixed intensity for a couple wavelength $\lambda_{\mathrm{ex}}, \lambda_{\mathrm{em}}$ could lead to errors in complexing properties determination. To avoid misinterpretation, several works have used all the information present in EEMF to extract fluorescent compounds before data treatment of the fluorescence quenching experiment. This decomposition of EEMF set has first been done by principal component analysis (PCA) on synchronous spectra (Esteves da Silva and Machado 1995), or on fluorescence matrices using SIMPLISMA software (Smith and Kramer. 1999, 2000). More recently chemometric methods have been used in order to extract useful information like the Multivariate Curve Resolution-Alternating Least Squares (MCR-ALS) (Antunes et al. 2007) or the statistical PARAFAC method (Murphy et al. 2008; Luciani et al. 2008). These statistical methods enable the decomposition using the multiple EEMF of the fluorescence quenching experiment itself.

Fluorescence quenching of ligands is defined by the decreasing, or enhancement, of the fluorescence intensity in presence of cations or anions. The association of FDOM and the ion species lead to the formation of a metal-ligand complex species. This compound generally has a fluorescence quantum yield lower than the free ligand, except for some cations like $\mathrm{Al}^{3+}$ (Esteves da Silva and Machado 1996; Smith and Kramer 1999). When there is only one ligand present in a solution, the relation between the free ligand (L), the complexed ligand (ML) and the free metal $(\mathrm{M})$ concentration is characterised by a second degree equation which is dependant on the total concentration of ligand $\left(\mathrm{L}_{\mathrm{T}}\right)$, metal $\left(\mathrm{M}_{\mathrm{T}}\right)$ and the conditional equilibrium constant $\left(\mathrm{K}_{\mathrm{ML}}\right)$ (Ryan and Weber 1982). In this case determination of $K_{M L}$ and $\mathrm{L}_{\mathrm{T}}$, when $\mathrm{M}_{\mathrm{T}}$ is known, could be obtained by a simple treatment (Dudal et al. 2006), a quadratic calculus (Cabaniss and Shuman 1988; Esteves da Silva et al. 1998) or by a numerical determination of $K_{M L}$ and $L_{T}$ (Smith and Kramer 1998, 1999, 2000). When N ligands are present $(\mathrm{N}>2)$ the number of equation increases and the solution is obtained by numerical 
optimisation (Smith and Kramer 2000; Garnier et al. 2004). In this work the software PROCESE (Programme d'Optimisation et de Spéciation Chimique dans l'Environnement) is used as new simultaneous multi-response approach that enables the evaluation of the $\mathrm{N}$ ligands concentrations and their stability constants (Garnier et al. 2004; Louis et al. 2009).

Moreover, in case of natural sample, it is difficult to determine previously the number of ligands $(\mathrm{N})$ which is often empirically determinated based on spectroscopy deduction (Smith and Kramer 2000) or using the usage of the lowest number of parameter to fit the experimental data well (Esteves da Silva and Machado 1995). This number $N$ could vary from 1 (Ryan and Weber 1982; Esteves da Silva et al. 1998) to 4 ligands (Antunes et al. 2007) depending on the measurement method, the titration range, and the number of independent measured data. Moreover, during quenching experiment, it is very difficult to determine the quantum yield of each species because pure species solutions do not exist. Particularly, in the natural samples, the initial total concentration of cations is intrinsic, therefore, the initial state of FDOM is unknown.

This work proposes a fluorescence quenching experiment base on a logarithmic metal addition that allows a wide range of total metal concentration between $1.7 \times 10^{-9}$ to $10^{-3} \mathrm{~mol}^{-1}$. Usual data treatment of Ryan and Weber (1982) method is compared with a PARAFAC treatment to directly deal with component entities. Instead of a partial and systematic determination of the number of fluorescent ligands for fluorescence quenching modelling this experiment leads to an optimum exploitation of the entire EEMF data.

\section{Instrumentation and experiments}

Fluorescence quenching has been done on a surface water sample from an Amazonian tropical river (Rio Negro at Sao Gabriel da Cachoeira, Brazil). Two litres were filtered on site with a burned glass filter, poisoned with sodium azide (final concentration of $0.5 \times 10^{-3} \mathrm{~mol}^{-1}$ ) and conserved in a glass flask at $4^{\circ} \mathrm{C}$ in dark. This sample presents a concentration of dissolved organic carbon $20 \mathrm{mg} \mathrm{Cl}^{-1}$, an important fluorescent response and an initial concentration of copper of $1.7 \times 10^{-9} \mathrm{~mol}^{-1}$ measured by differential pulse anodic stripping voltametry after UV irradiation $(\mathrm{pH}=2)$ by a low pressure mercury lamp to eliminate any complexation with organic matter (Louis et al. 2009). In order to avoid the Inner Filter Effect (Luciani et al. 2009), a 8 times dilution with MQ water has been applied to the sample before the fluorescence quenching experiment. A $29.2 \mathrm{ml}$ volume of diluted sample was spiked by 50 additions of microvolume of four copper nitrate standard solutions.
Fig. 1 Total copper concentrations during fluorescence quenching experiment

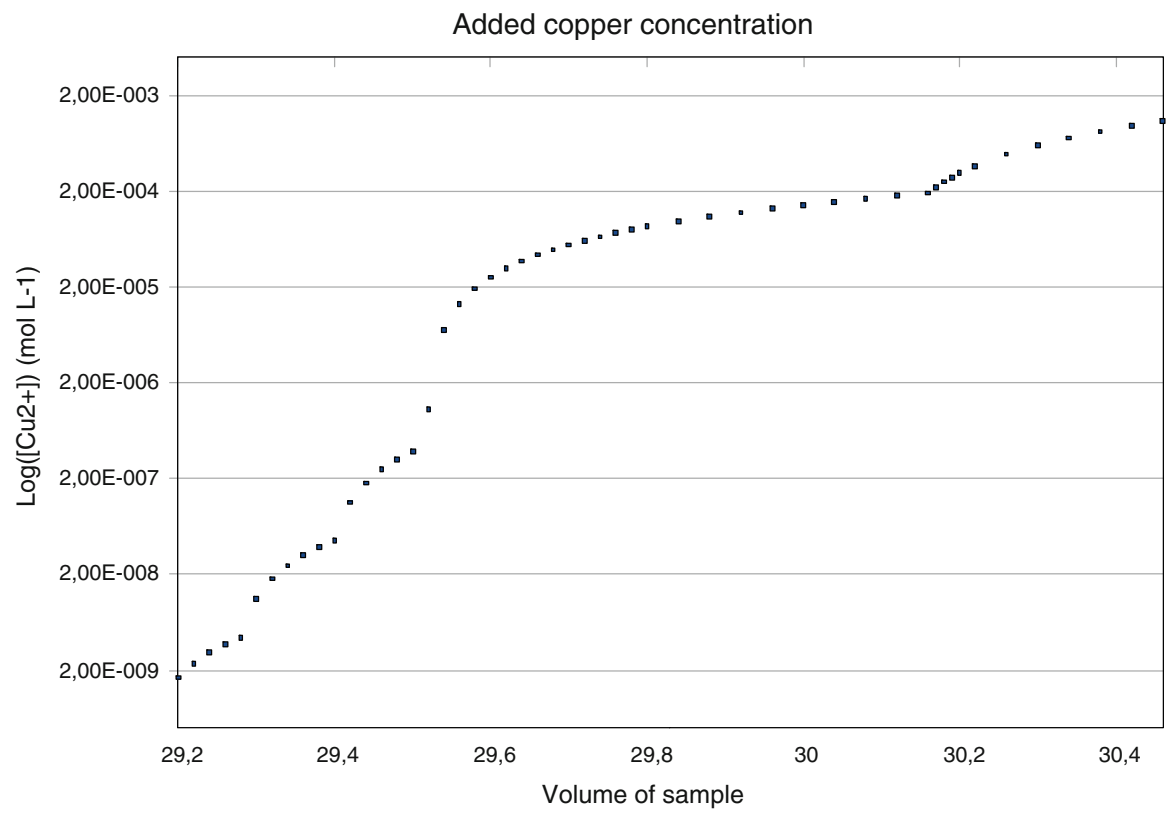


The different concentrations $\left(10^{-6}, 10^{-5}, 9.10^{-4}\right.$ and $9.10^{-3} \mathrm{~mol} \mathrm{l}^{-1}, \mathrm{Cu}\left(\mathrm{NO}_{3}\right)_{2}$ analytical grade in MQ water) were used to cover a wide range of total copper concentrations, from the initial concentration to $10^{-3}$ mol $1^{-1}$, by constant increments of the logarithm of the total copper concentration (Fig. 1). These logarithmic increases improved accuracy of the method and allowed to obtain a better determination of the complexing properties for the lowest concentrations as well as for the highest ones (Garnier et al. 2004). Additions were done in an acid cleaned Teflon bottle (Nalgene). Previous experiments show that for all additions, $30 \mathrm{~min}$ of stabilisation under agitation is sufficient to reach the fluorescence stabilisation (Louis et al. 2009). The $\mathrm{pH}$ and $3 \mathrm{D}$ fluorescence matrices were measured $\left(T=22^{\circ} \mathrm{C}\right)$ in a $3 \mathrm{ml}$ Suprasil standard quartz cell.

All measured spectra were obtained with a fluorometer Hitachi F4500. EEMF of the solutions were recorded at $2,400 \mathrm{~nm} / \mathrm{min}$ scan speed from 250 to $600 \mathrm{~nm}$ in emission by step of $5 \mathrm{~nm}$ and for an excitation wavelength from 200 to $500 \mathrm{~nm}$ by step of $5 \mathrm{~nm}$. Excitation and emission bandwidth were $10 \mathrm{~nm}$. Fluorescence intensity was corrected from detector response using manufacturer's setting. Data for EEMF treatment was extracted by FLWinLab software for emission and excitation range stepped every $5 \mathrm{~nm}$. Rayleigh and Raman physical diffusion of light were numerically removed by the method proposed by Zepp et al. (2004). During the experiment, the $\mathrm{pH}$ is maintained at natural level, around $6.0 \pm 0.1$ and nitrogen bubbling purges the experiment from dissolved oxygen. The quenching dilution factor was under 1.2, and dilution correction of intensity was systematically done during the data treatment of fluorescence intensity.

Once all the EEMF were collected, two data treatments were done: PARAFAC and classical. For the PARAFAC treatment, all the measured EEMF of the experiment were treated to obtain the fluorescent components present in solution and their relative contribution to total fluorescence (Luciani et al. 2008; Murphy et al. 2008). Using these results an equilibrium optimization was done considering the component's contribution as a proportional proxy of the concentration of ligand in solution. For the classical treatment, multi-wavelength fluorescence intensity quenching was done on (excitation/emission) peak position $(332 / 450 \mathrm{~nm}),(260 / 450 \mathrm{~nm}),(230 / 340 \mathrm{~nm})$ and $(240 / 420 \mathrm{~nm})$ respective positions of humic-like (peak C), fulvic-like (peak A), protein moieties (peak $\mathrm{T})$ and a PARAFAC component $(\mathrm{M})$ as referenced by Coble (1996). All intensity measurements were expressed in percentage of the first intensity (Fig. 2). Once the contribution (PARAFAC) or the intensities (for classical) data are obtained, curves were modelled by the equilibrium optimization program PROCESE (Garnier et al. 2004) for simultaneous multi-ligands optimization according to the method of Ryan and Weber (1982).

\section{Results and discussion}

The initial EEMF of the sample shows the maximal fluorescence for humic-like region $(332 / 450 \mathrm{~nm})$,
Fig. 2 Relative fluorescence quenching intensity at $(336 / 450 \mathrm{~nm})$, $(260 / 450 \mathrm{~nm})$ and (230/ $340 \mathrm{~nm}$ ) of the Rio Negro sample from Sao Gabriel da Cachoeira (Brasil) $\left(\mathrm{pH}=6.0, T=22^{\circ} \mathrm{C}\right)$

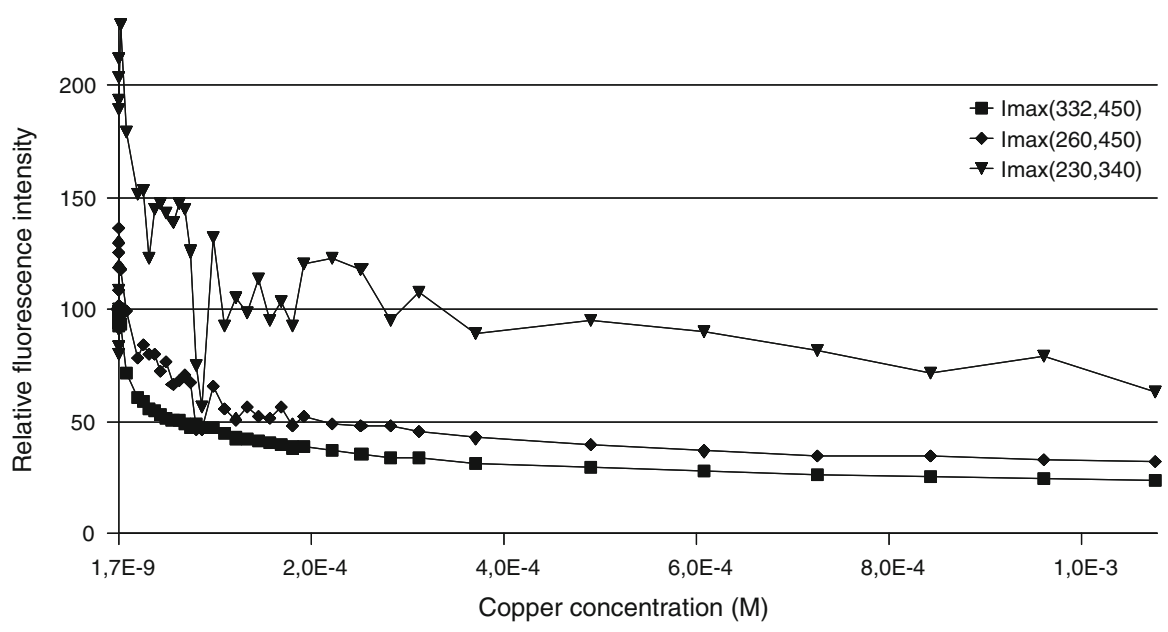


with a less important peak at $(260 / 450 \mathrm{~nm})$ representing the fulvic-like compounds. Protein-like region is masked by the higher intensity of the other two peak. These EEMF are typical of black water body from tropical region (Mounier et al. 1999b).

The results of the classical approach for the three observed domains during the quenching experiment are represented in Figs. 2 and 3. Quenching curve for the $(332 / 450 \mathrm{~nm})$ peak shows a well decreasing curve defined from $100 \%$ to $20 \%$ of the initial fluorescence, with low noise interference. This curve is similar to those obtained by Smith and Kramer (2000) for a Suwanee River Fulvic Acid solution. The fulviclike region gives a noisier curve at the beginning. Intensity appears to be higher than the initial value until $140 \%$, which is due to the excitation Xenon lamp low energy in UV area. After $2.0 \times 10^{-4}$ mol $1^{-1}$ of total cooper concentration a quasi linear decrease is observed until $30 \%$. For protein-like components, noise is considerable, giving intensity around $230 \%$ of the initial value. For proteins, the value is under $100 \%$ until $4.0 \times 10^{-4} \mathrm{~mol} \mathrm{l}^{-1}$, and decreases down to $60 \%$ at the end of experiment. As regards the initial logarithmic additions, the good signal stability is a fine point. The signal degradation occurs after $10^{-7} \mathrm{~mol} \mathrm{l}^{-1}$ of total copper concentration as shows by the logarithmic representation of the quenching curves (Fig. 3). At the beginning of the experiment from $1.7 \times 10^{-9}$ to $3.16 \times 10^{-7} \mathrm{~mol} \mathrm{l}^{-1}$ of total copper concentration, the phenomenon obviously corresponds to an adsorption or a complexation of the copper onto the system surface (Teflon flask, glass and quartz wall). When modelling all the points, it is necessary to introduce a very strong constant corresponding to this loading effect (data not shown). This forbids the study of the complexation upper $3.16 \times 10^{-7} \mathrm{~mol} \mathrm{l}^{-1}$ of total copper concentration, but allows the study of the complexing properties of the DOM above this limit (Luster et al. 1996). It is worth noting that this wall effect is detected for the first time in a fluorescence quenching experiment at such a wide range of copper concentration. All the results of this work will be treated for concentration above this limit $\left(3.16 \times 10^{-7} \mathrm{~mol} \mathrm{l}^{-1}\right)$ since it does not change the results for NOM complexing properties, at the exception of the effective copper concentration analytical window.

The bias errors between experimental and calculated fluorescence is given by bias which is equal to the sum of the absolute value of the difference between the logarithm of the experimental fluorescence intensity and the logarithm of the calculated fluorescence intensity. Results are shown in Table 1. Results using Ryan and Weber (1982) model with one ligand (Table 1), generally lead to a bad modelling (bias form 2.56-4.06) of the experimental data $\left(\mathrm{L}_{\mathrm{T}}=1.7 \times\right.$ $10^{-5}-5.7 \times 10^{-5} \mathrm{~mol} \mathrm{l}^{-1}$ and conditional constant $\left.\mathrm{K}_{\mathrm{L}}=10^{4.0}-10^{4.4}\right)$. The one ligand fitting on Fig. 4 (dotted lines), gives evidence that model 1:1 is not sufficient. This implies that it is necessary to have more than one ligand. For the four fluorescence responses, using à 2 ligands model, it gives a bias from 0.38 to 3.03 which is better for all fluorescence position (Fig. 4, plain lines). The strongest ligands
Fig. 3 Logarithmic scale for fluorescence quenching intensity at $(336 / 450 \mathrm{~nm})$, $(260 / 450 \mathrm{~nm})$ and $(230 /$ $340 \mathrm{~nm}$ ) of the Rio Negro sample from Sao Gabriel da Cachoeira (Brasil) $(N=51)$ $\left(\mathrm{pH}=6.0, T=22^{\circ} \mathrm{C}\right)$

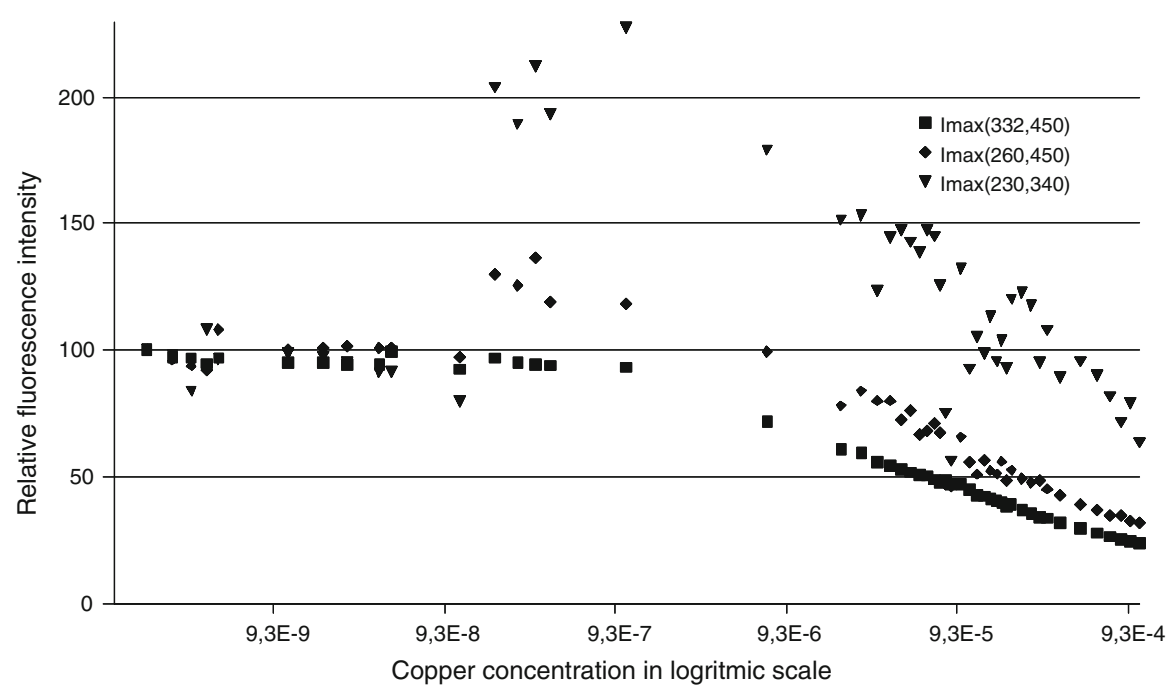


present conditional constant from $10^{4.7}$ to $10^{5.7}$ instead of the weaker from $10^{3.3}$ to $10^{3.9}$. The lowest concentration is found for the peak $\mathrm{M}$ intensity $\left(\mathrm{L}_{1,240 / 420}=6.6 \times 10^{-6} \mathrm{~mol} \mathrm{l}^{-1}, \mathrm{~K}_{1,240 / 420}=10^{4.8}\right)$ whereas the higher corresponds to the weak ligand at the fluorescence position of the peak $\mathrm{A}\left(\mathrm{L}_{2,250 /}\right.$

Table 1 Binding parameters obtained by PROSECE fitting of multi-response fluorescence quenching of peak $\mathrm{C}, \mathrm{A}, \mathrm{M}, \mathrm{P}$, using one ligand and two ligands systems

\begin{tabular}{lllllll}
\hline Model & Peak & $\begin{array}{l}\mathrm{L}_{1} \\
(\mathrm{~mol} / \mathrm{l})\end{array}$ & $\log \left(\mathrm{K}_{1}\right)$ & $\begin{array}{l}\mathrm{L}_{2} \\
(\mathrm{~mol} / \mathrm{l})\end{array}$ & $\log \left(\mathrm{K}_{2}\right)$ & Bias \\
\hline $1 \mathrm{~L}$ & Peak A & $1.7 \mathrm{E}-5$ & 4.4 & & & 2.56 \\
& Peak C & $4.6 \mathrm{E}-5$ & 4.0 & & & 2.78 \\
& Peak P & $2.9 \mathrm{E}-5$ & 4.3 & & & 3.13 \\
& Peak M & $5.7 \mathrm{E}-5$ & 4.2 & & & 4.06 \\
$2 \mathrm{~L}$ & Peak A & $8.1 \mathrm{E}-6$ & 5.5 & $4.2 \mathrm{E}-4$ & 3.9 & 1.94 \\
& Peak C & $7.6 \mathrm{E}-6$ & 5.7 & $1.6 \mathrm{E}-4$ & 3.8 & 0.38 \\
& Peak P & $7.1 \mathrm{E}-6$ & 4.7 & $1.5 \mathrm{E}-4$ & 3.3 & 2.95 \\
& Peak M & $6.0 \mathrm{E}-6$ & 4.8 & $2.9 \mathrm{E}-4$ & 3.4 & 3.03 \\
\hline
\end{tabular}

$450=4.2 \times 10^{-4}, \mathrm{~K}_{2,250 / 450}=10^{3.9}$ ). For all fluorescence positions the stronger ligand appears to be the less concentrated whatever its position. Like previous studies on copper fluorescence quenching experiments undertaken with FDOM (Grimm et al. 1991; Seritti et al. 1994; Luster et al. 1996; Antunes et al. 2007), our results on strong ligands confirm the trend for the conditional constant around $10^{5}$ with ligand concentration around $10^{-6} \mathrm{~mol} \mathrm{l}^{-1}$. Results for the weak ligands (around 10 $0^{3.6}$ ) are lower than those found in literature with a very high concentration around $10^{-4} \mathrm{~mol} \mathrm{l}^{-1}$.

PARAFAC treatment gives optimum results for two components using decision tools described in Luciani et al. (2008). Component 1 presents an excitation wavelength at $230 \mathrm{~nm}$ and an emission maximum at 420-425 nm. Component 2 shows two excitation wavelength at 255 and $350 \mathrm{~nm}$ and a unique emission maximum at $475 \mathrm{~nm}$ (Fig. 5). These two components are sufficient to explain all the EEMF during the quenching titration and this result corresponds to a
Fig. 4 PROSECE fitting of multi-response fluorescence quenching (diamond) at $\lambda_{\mathrm{ex}} / \lambda_{\mathrm{em}}$ wavelengths $332 / 450 \mathrm{~nm}$ (upper left: peak C), 260/450 nm (upper right: peak A), 240/420 nm (down left: peak M), 230/340 nm (down right: peak $\mathrm{P}$ ), using one ligand (dotted line) and two ligands (full line) systems. Inserted graph: error (in \%) of calculated intensities versus total copper concentration for one ligand (filled square) and two ligands (open square) systems
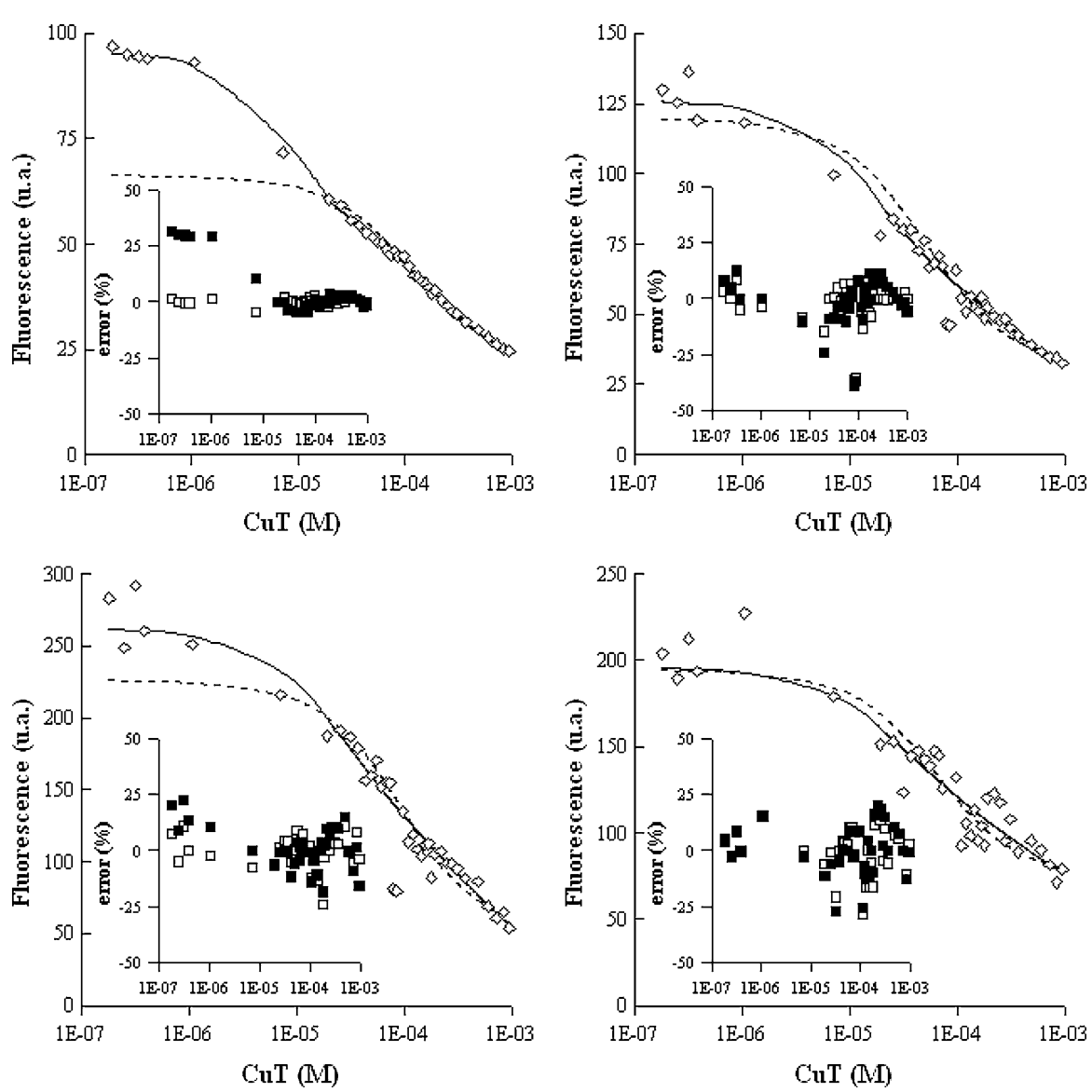

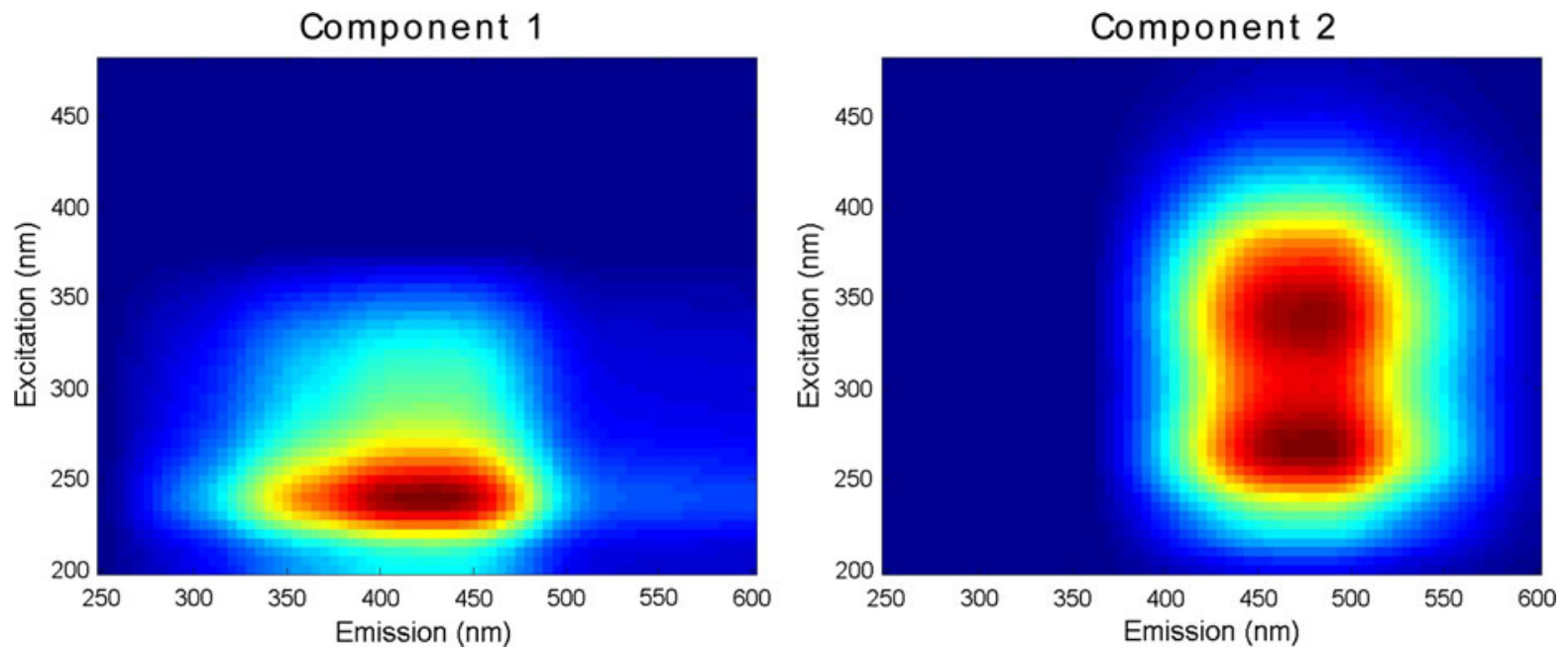

Fig. 5 PARAFAC component from the 51 experimental fluorescence quenching

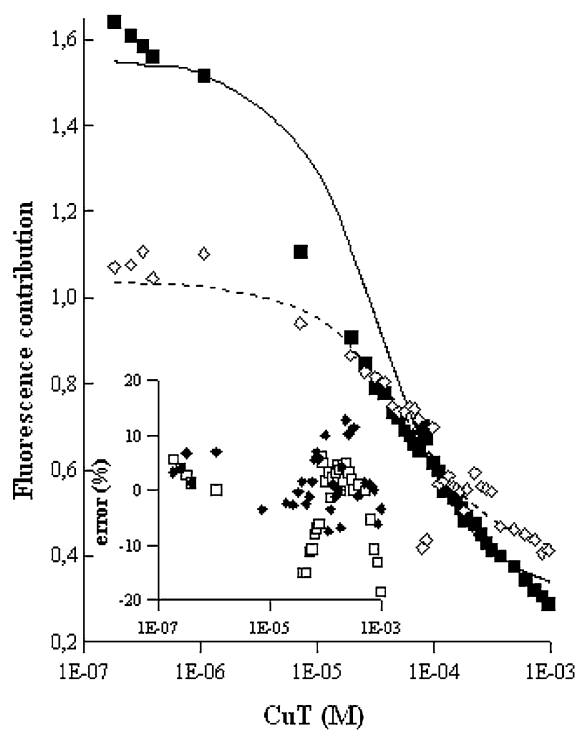

Fig. 6 PROSECE fitting of contribution to the fluorescence of PARAFAC component 1 (experimental: open diamond, calculated: dotted line) and 2 (experimental: filled square, calculated: full line). Left graph: the chemical system is composed of 2 ligands (L1/comp1 and L1/comp2). L1/comp1 contributes to the fluorescence of PARAFAC component 1, L1/ comp2 to the one of component 2. Right: the chemical system

unique statistical solution (Luciani et al. 2008). Both components 1 and 2 are consistent with UV (component 1 and part of the component 2) and visible (component 2) humic-like compounds (Coble 1996; Smith and Kramer 1999). They are often present in NOM's EEMF (Murphy et al. 2006, 2008). Component 2 shows slight red shift for emission wavelength. For

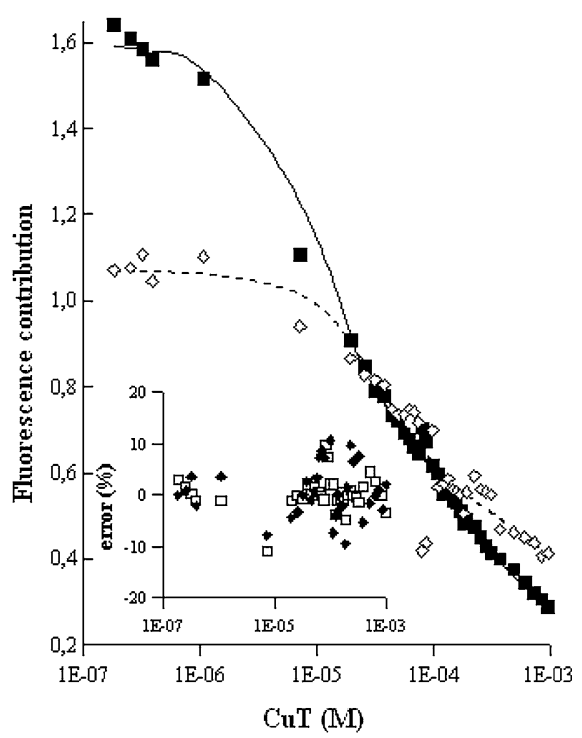

is composed of four ligands (L1/comp1, L1/comp2, L2/comp1, L2/comp2). L1/comp1 and L2/comp1 contribute to the fluorescence of PARAFAC component 1, L1/comp2 and L2/ comp2 to the one of component 2 (see explanation in the text). Insert graph: error (in \%) of calculated intensities versus total copper concentration for the PARAFAC component 1 (filled diamond) and 2 (open square)

the two components, a variation is observed during the fluorescence quenching experiment (Fig. 6) meaning that no unquenched component was detected.

Once these components extracted, the contribution of each component to each EEMF measurement is calculated (Fig. 6). The participation of the two components are used in a multi-response treatment 
where the complexing parameters are calculated. Each component represents normally a unique independent ligand which in contribution respects the Ryan and Weber (1982) conditions, i.e. quenching fluorescence has to be proportional to the complex concentration. This contribution to total fluorescence enables to calculate the complexing properties of each component (Fig. 6, left graph). The sigmoid shape is for both components consistent with the 1:1 complexation model (Grimm et al. 1991). This decreasing contribution to fluorescence is linked with the formation of a complex with metal that modifies the ligand's quantum yield of fluorescence. Consequently, this modifies the EEMF of the solution. The site concentrations calculated for the component 1 and 2 give respectively $\left(\mathrm{L}_{1 / \text { comp } 1}=12 \times 10^{-6} \mathrm{~mol} \mathrm{l}^{-1}, \quad \mathrm{~K}_{1 / \text { comp } 1}=10^{4.3}\right)$ and $\left(\mathrm{L}_{1 / \mathrm{comp} 2}=4.1 \times 10^{-6} \mathrm{~mol} \mathrm{l}^{-1}, \quad \mathrm{~K}_{1 / \mathrm{comp} 2}=\right.$ $\left.10^{4.6}\right)$. The bias for this fitting model give a value of 5.21. Since this bias is calculated from the two contribution curves, it is not possible to compare it with the cases of two ligands in Table 1 . However, by observing the errors distribution (Fig. 6, left graph) it is obvious that two independent ligands are not sufficient to fit the experimental points. To obtain a better modelling of the PARAFAC components, it is possible to consider that two complexing sites on each component exist. This gives results for four simultaneous ligands model (Fig. 6, right graph) with a lower bias (3.03) and a better error distribution.

On one hand, the new parameters give component 1 a strong ligand $\left(\mathrm{L}_{1 / \mathrm{comp} 1}=7.0 \times 10^{-6}\right.$ and $\mathrm{K}_{1 /}$ comp $\left.1=10^{5.0}\right)$ and a weak one $\left(\mathrm{L}_{2 / \mathrm{comp} 1}=1.3 \times 10^{-4}\right.$ and $\mathrm{K}_{1 / \mathrm{comp} 2}=10^{2.8}$ ) and on another hand for component 2 a strong ligand $\left(\mathrm{L}_{2 / \text { comp } 1}=9.2 \times 10^{-6}\right.$ and $\left.\mathrm{K}_{2 / \mathrm{comp} 1}=10^{5.8}\right)$ and a weak one $\left(\mathrm{L}_{2 / \mathrm{comp} 2}=\right.$ $1.7 \times 10^{-4}$ and $\mathrm{K}_{2 / \mathrm{comp} 2}=10^{3.9}$ ) (Table 2). Since independent components 1 and 2 represent the whole fluorescence response variation, results give the parameters of the fluorescent complexing entities present in the sample that can be studied by a fluorescence quenching experiment.

PARAFAC decomposition confirms that there is only 2 fluorescent sites that contribute to the metal binding process for this metal concentration range. Both $\mathrm{K}_{1 / \text { comp } 1}$ and $\mathrm{K}_{1 / \text { comp2 }}$ fit around the usual conditional constant value found for copper $\left(10^{5}\right)$. As these components represent the entire fluorescence response, we can consider they represent all the fluorescent complexing sites and by summing them up one obtains the complexing properties of sample: For strong ligands $\mathrm{L}_{1 \mathrm{~T}}=16.2 \times 10^{-6} \mathrm{~mol} \mathrm{l}^{-1}$ and for weak ligands $\mathrm{L}_{2 \mathrm{~T}}=3.0 \times 10^{-4} \mathrm{~mol} \mathrm{l}^{-1}$. The PARAFAC approach gives a higher concentration than the classical approach $\left(6.0-8.1 \times 10^{-6} \mathrm{~mol} \mathrm{l}^{-1}\right)$ with conditional constant ranging around $10^{5}$.

It is important to note that the bias for component 1 and 2 (respectively 5.21 or 3.03 ) is higher than the bias obtained for the peak $\mathrm{C}(0.38)$ modelled with two independent ligands. This is understandable because all the data fluorescence information is used by PARAFAC to obtain results for comp1 and comp2. This method also integrates the statistical variability of the fluorescence response, whereas peak $\mathrm{C}$ domain specifically focuses on fluorescence signals with low variability, neglecting a part of the phenomenon. Moreover, PARAFAC treatment of the fluorescence quenching experiment allows us to manipulate these parameters like components, which is not possible with the classical method. Hence, based on the same fluorescence quenching experiment of the NOM of the Rio Negro at Sao Gabriel da Cachoeira, results of both methods may appear to be different but they actually depend on data treatment. Assuming that PARAFAC treatment extracts unique components, the complexing parameters of this sample are described (Table 2).

Table 2 Binding parameters obtained by PROSECE fitting of simultaneous multi-response fluorescence quenching of components 1 and 2, using one ligand and two ligands model

\begin{tabular}{|c|c|c|c|c|c|c|}
\hline Model & PARAFAC component & $\mathrm{L}_{1}\left(\mathrm{~mol} \mathrm{l}^{-1}\right)$ & $\log \left(\mathrm{K}_{1}\right)$ & $\mathrm{L}_{2}\left(\mathrm{~mol} \mathrm{l}^{-1}\right)$ & $\log \left(\mathrm{K}_{2}\right)$ & Bias \\
\hline \multirow[t]{2}{*}{$1 \mathrm{~L} \& 1 \mathrm{~L}$} & Component 1 & $1.2 \mathrm{E}-5$ & 4.3 & & & 5.21 \\
\hline & Component 2 & $4.1 \mathrm{E}-6$ & 4.6 & & & \\
\hline \multirow[t]{2}{*}{$2 \mathrm{~L} \& 2 \mathrm{~L}$} & Component 1 & $7.0 \mathrm{E}-6$ & 5.0 & $1.3 \mathrm{E}-4$ & 2.8 & 3.03 \\
\hline & Component 2 & $9.2 \mathrm{E}-6$ & 5.8 & $1.7 \mathrm{E}-4$ & 3.9 & \\
\hline
\end{tabular}




\section{Conclusion}

Three dimensional fluorescence allows a rapid approach of the metal-NOM complex formation by using fluorescence quenching. PARAFAC pretreatment enables us to reduce the system to a well defined number of fluorescent ligands that could be manipulate in respect of the Ryan and Weber (1982) assumption. Results even show that each component is unique; it gives better results when considering two complexing sites on each component. No unaffected ligand was present in the studied sample, all the components, 1 and 2 , are quenched by the copper addition. However, the results show that if we consider one complexing site for one component it is not sufficient. Thanks to a trace metal addition experiment, fluorescence quenching turn out to be effective in detecting a surface adsorption problem for this type of experiment, limiting the total copper concentration useful range at a lower frontier to $3.16 \times 10^{-7} \mathrm{~mol} \mathrm{l}^{-1}$ in this case. If researchers want to study the strongest trace fluorescent sites of FDOM, it is important for further fluorescence quenching experiments with trace metal concentration titration to take into account the wall absorption. As PARAFAC gives a unique solution, inspite of its noisier results, we support this EEMF quenching data treatment to gives results that represent a unique solution and a more realistic evaluation of the complexing parameters.

Acknowledgement This research was partly supported by the ARCUS 2006 Projet Provence-Alpes-Côte-d'Azur/Brésil, «Construction d'un espace scientifique et technologique PACA/Brésil ».

\section{References}

Antunes MCG, Pereira CCC, Esteves da Silva JCG (2007) MCR of the quenching of the EEM of fluorescence of dissolved organic matter by metal ions. Anal Chim Acta 595: 9-18

Cabaniss SE (1992) Synchronous fluorescence spectra of metal-fulvic acid complexes. Environ Sci Technol 6: 1133-1139

Cabaniss SE, Shuman MS (1988) Copper binding by dissolved organic matter: I. Suwannee River fulvic acid equilibria. Geochim Cosmochim Acta 52:185-193

Coble PG (1996) Characterization of marine and terrestrial DOM in sea water using excitation-emission matrix spectroscopy. Mar Chem 51:325-346
Dudal Y, Holgado R, Maestri G, Guillon E, Dupont L (2006) Rapid screening of DOM's metal-binding ability using a fluorescence-based microplate assay. Sci Total Environ 354(2-3):286-291

Esteves da Silva JCG, Machado AASC (1995) Evolving factor analysis of synchronous fluorescence spectra of humic substances in the presence of $\mathrm{Cu}$ (II). Chemom Intell Lab 27:115-128

Esteves da Silva JCG, Machado AASC (1996) Characterization of the binding sites for $\mathrm{Al}(\mathrm{III})$ and $\mathrm{Be}(\mathrm{H})$ in a sample of marine fulvic acids. Mar Chem 54:293-302

Esteves da Silva JCG, Machado AASC, Silva CSPCO (1996) Simultaneous use of evolving factor analysis of fluorescence spectral data and analysis of $\mathrm{pH}$ titration data for comparison of the acid-base properties of fulvic acids. Anal Chim Acta 318:365-372

Esteves da Silva JCG, Machado AASC, Oliveira CJS, Pinto MSSDS (1998) Fluorescence quenching of anthropogenic fulvic acids by $\mathrm{Cu}(\mathrm{II}), \mathrm{Fe}(\mathrm{III})$ and $\mathrm{UO}_{2}{ }^{2+}$. Talanta 45 : 1155-1165

Garnier C, Pižeta I, Mounier S, Benaim JY, Branica M (2004) Influence of the type of titration and of data treatment methods on metal complexing parameters determination of single- and multi-ligand systems measured by stripping voltametry. Anal Chim Acta 505(2):263-275

Grimm M, Azarraga LV, Carreira LA, Susetyo W (1991) Continuous multiligand distribution model used to predict the stability constant of $\mathrm{Cu}$ (II) metal complexation with humic material from fluorescence quenching data. Environ Sci Technol 25(8):1427-1431

Louis Y, Garnier C, Lenoble V, Omanović D, Mounier S, Pižeta I (2009) Characterisation and modelling of marine dissolved organic matter interactions with major and trace cations. Mar Environ Res 67(2):100-107

Luciani X, Mounier S, Paraquetti HHM, Redon R, Lucas Y, Bois A, Lacerda LD, Raynaud M, Ripert M (2008) Tracing of dissolved organic matter from the SEPETIBA Bay (Brazil) by PARAFAC analysis of total luminescence matrices. Mar Environ Res 65:148-157

Luciani X, Mounier S, Redon R, Bois A (2009) A simple correction method of inner filter effects affecting FEEM and its application to the PARAFAC decomposition. Chemom Intell Lab 96:227-238

Luster J, Lloyd T, Sposito G, Fry IV (1996) Multi-wavelength molecular fluorescence spectrometry for quantitative characterization of copper(II) and aluminium(III) complexation by dissolved organic matter. Environ Sci Technol 30:1565-1574

Manciulea A, Baker A, Lead JR (2009) A fluorescence quenching study of the interaction of Suwannee River fulvic acid with iron oxide nanoparticles. Chemosphere 76:1023-1027

Mounier S, Braucher S, Benaim JY (1999a) Differentiation of dissolved organic matter's properties of the Rio Negro basin by cross flow ultra-filtration and UV-spectrofluorescence. Water Res 33(10):2363-2373

Mounier S, Patel N, Quilici L, Benaim JY, Benamou C (1999b) Three-dimensional fluorescence of the dissolved carbon in the Amazon River. Water Res 33(6):1523-1533

Murphy KR, Ruiz GM, Dunsmuir WTM, Waite TD (2006) Optimized parameters for fluorescence-based verification 
of ballast water exchange by ships. Environ Sci Technol 40(7):2357-2362

Murphy KR, Stedmon CA, Waite TD, Ruiz GM (2008) Distinguishing between terrestrial and autochthonous organic matter sources in marine environments using fluorescence spectroscopy. Mar Chem 108:40-58

Ryan DK, Weber JH (1982) Fluorescence quenching titration for determination of complexing capacities and stability constant of fulvic acid. Anal Chem 54(6):986-990

Seritti A, Morelli E, Nannicini L, Giambelluca A, Scarano G (1994) Fluorescence emission characteristics of naturally occurring organic matter in relation to metal complexation studies. Sci Total Environ 148:73-81

Smith DS, Kramer JR (1998) Multi-site aluminum speciation with natural organic matter using multiresponse fluorescence data. Anal Chim Acta 363:21-29
Smith DS, Kramer JR (1999) Fluorescence analysis for multisite aluminium binding to natural organic matter. Environ Int 25(2-3):307-314

Smith DS, Kramer JR (2000) Multisite metal binding to fulvic acid determined using multiresponse fluorescence. Anal Chim Acta 416:211-220

Zepp RG, Sheldon WM, Moran MA (2004) Dissolved organic fluorophores in southeastern US coastal waters: correction method for eliminating Rayleigh and Raman scattering peaks in excitation-emission matrices. Mar Chem 89: $15-36$ 